\title{
A Prática das Correspondências no Design: Objetos do Corpo, Corpobjeto
}

\section{The Practice of Correspondence in Design: Objects from the body, Bodyobject}

Adriana Dornas, MuC / Museu da Cadeira Brasileira.

adrianadornasmoura@gmail.com

Angélica Adverse / Universidade Federal de Minas Gerais.

adverseangelica@gmail.com

Maira Gouveia / Universidade do Estado de Minas Gerais.

mairagouveia@gmail.com

\section{Resumo}

A partir do sentido da prática de correspondências examinamos como o design introduz uma reflexão sobre o uso e a funcionalidade. Pretendemos colocar em relevo as relações poéticas e simbólicas entre os objetos e os corpos. Para tanto, elegemos as cadeiras vestíveis (wearables chairs) a fim de analisarmos as distintas experiências decorrentes do processo de uma (re)semântica do objeto no design e das roupas relacionadas às experiências estéticas da moda. Apresentaremos como a ação de vestir uma cadeira possibilita ao usuário confrontar a dimensão cotidiana do objeto de design, articulando progressivamente os elementos artísticos concernentes à poiesis, à plástica e à linguagem. O fulcro do texto é pensar a criação de conceitos ligados à transformação do modo de existência dos corpos e dos objetos.

Palavras-chave: Prática das Correspondências, Corpobjeto, Cadeira Vestível

\section{Abstract}

Based on the sense of correspondence practice, we examine how design introduces a reflection on use and functionality. We intend to highlight the poetic and symbolic relationships between objects and bodies. To this end, we chose wearable chairs in order to analyze the different experiences resulting from the process of (re)semantics of the object in design and the clothes related to the aesthetic experiences of fashion. We will present how the action of dressing a chair allows the user to confront the everyday dimension of the design object, progressively articulating the artistic elements concerning to the poiesis, to the plastic and to the language. The focus of the text is to think about the creation of concepts linked to the transformation of the way of existence of bodies and objects.

Keywords: Correspondence Practice, Bodyobject, Wearable Chair 


\section{Introdução}

E se as coisas pudessem falar? O que diriam? Ou elas já falam e nós apenas não a escutamos? E quem irá traduzi-las? (...) Segundo Benjamin, essa linguagem das coisas é muda, é mágica e seu meio é uma comunidade material. Assim, devemos assumir que existe uma linguagem de pedras, panelas e caixas de papelão. Lâmpadas falam como se habitadas por espíritos (...)

Hito Steyerl

Na modernidade industrial, tudo o que poderia articular-se ao espírito foi, segundo Benjamin (2013), transformado em cultura. A cultura expressa um conjunto de práticas que constituem as experiências históricas, concentrando em seu cerne as contradições da vida moderna. As linguagens que se originaram desse momento histórico distanciaram-se gradativamente da essência das coisas ${ }^{1}$. Os objetos tornaram-se mais ricos em funcionalidade, mas a experiência relacional dos artefatos com a humanidade tornou-se empobrecida. O fetiche da mercadoria foi potencialmente estimulado pelo consumo conspícuo, deslocando o significado das coisas para as mitologias $^{2}$. O valor de exposição dos objetos no mercado substituiu a relação afetiva e, gradativamente, a instância memorial que alicerçava as correspondências poéticas entre os usuários e os objetos foi sendo substituída pelo valor de troca. A aesthesis subordinou-se à função, enfraquecendo a essência espiritual da língua das coisas.

Como nos explica Benjamin, nós perdemos a capacidade de compreender que a linguagem dos objetos não é senão a mais pura expressão do espírito humano. Para o autor, se conseguíssemos desenvolver métodos que propusessem uma correspondência entre a linguagem humana e a linguagem das coisas, nós poderíamos restituir o conteúdo poético relacionado à simbologia dos objetos. Essa capacidade de tradução da língua das coisas poderia nos levar a (re)semantizar sua linguagem, espiritualizando a experiência relacional por elas desencadeada. Partindo dessa ideia benjaminiana sobre a linguagem geral e a experiência relacional, nós pretendemos pensar a prática da correspondência entre os objetos do design e as roupas da moda.

A intenção do artigo é pensar a retomada da prática das correspondências, advinda da filosofia de Swedenborg, para compreender a comunicação estabelecida por meio da criação de wearable em projetos interdisciplinares e transdisciplinares. Esse pensamento foi utilizado nas

\footnotetext{
${ }^{1}$ Compreendemos o sentido de coisa a partir da ideia de Heidegger (1992, p.45): "como um suporte que apresenta propriedades e a verdade que lhe corresponde tem o seu lugar no enunciado, na proposição, que é uma ligação entre um sujeito e um predicado". Nessa linha de pensamento, a coisa é uma conexão derivada de uma correspondência efetuada. A coisa seria o que nos direciona ao descobrimento da essência de toda proposição.

${ }^{2}$ A mitologia moderna teria uma leitura ambivalente, segundo Benjamin, podendo tanto (re)encantar o mundo a partir da transfiguração das coisas quanto modificar a história pela reificação.
} 
experimentações da vanguarda artística do século XIX e do início do século XX a fim de se estruturar a essência espiritual das coisas, o que leva Beyaert-Geslin (2011) a pensar a transformação do sentido de interface, possibilitando uma reflexão crítica entre os objetos e os usuários e, ainda, fomentar o diálogo das coisas de maneira a criar uma correspondência semântica da interface-objeto com a interface-sujeito.

Apresentamos um estudo sobre a prática das correspondências no design a partir do processo de relação entre os corpos e os objetos. Selecionamos, neste texto, alguns estudos referentes às interlocuções entre o design, a moda e a arte para pensarmos a correspondência de práticas de projeto que visavam pensar o dialogo semântico entre o objeto do mobiliário (cadeira) e os objetos do vestuário (roupas). Na medida em que uma cadeira corresponde ao vestuário, ela pode exprimir as diferenças semânticas do corpo em movimento com a roupa ou ainda pela forma do corpo assentado em uma cadeira. A criatividade se instaura no instante em que novas formas de existência podem ser pensadas para o corpo e para a criação de objetos no design. Nesse aspecto, podemos compreender a diferença entre os campos de criação da moda e do design porque propõem uma experiência prática distinta, isto é, a gestualidade das formas da cadeira pode determinar novas modelagens para o corpo, contribuindo para a transformação das estratégias práticas do modo de uso das roupas.

\section{O Avesso do Desenho [a prática das correspondências no design]}

A relação entre os corpos e os objetos foi amplamente apresentada na literatura do século XIX. Do Romantismo ao Decadentismo, apresentou-se uma semântica dos objetos a partir da qual as trocas simbólicas mediavam os significados orientando novas práticas sociais. Neste ponto, revelaram-se como os corpos e os objetos exprimiam o ethos da cultura material em nossa existência. Como não lembrar de algumas passagens do romance Às Avessas (1884), de Huysmans, nas quais a descrição minuciosa do mobiliário e das roupas revelam uma experiência estética instaurada no cotidiano de maneira a aproximá-lo da arte? A descrição dos objetos do Art Nouveau, realizada no romance, não tem como objetivo enfatizar o contexto pragmático dos utensílios necessários à manutenção da vida, mas articulá-los às significações estéticas e simbólicas que fabulam uma nova realidade para a relação entre os corpos e os objetos. A passagem do romance na qual a personagem Des Esseints, elegantemente vestida, mimetiza-se constantemente com a sua cadeira apresenta-nos a paixão pelo artifício de maneira a integrar a sua vida aos objetos que a cercavam em sua reclusão monástica. Em determinado trecho, Des Esseints explica sua decisão de confinamento domiciliar: "Para que movimentar-se quando se pode viajar tão magnificamente numa cadeira?" (HUYSMANS, 1987, p.170)

A partir dessa passagem compreendemos a prática das correspondências poéticas construídas pela personagem ao propor analogias entre sons e sabores, entre as cores e as formas, entre o movimento dos corpos e a ciência dos odores. Essas alegorias aludiam aos poetas latinos e, 
obviamente, às noções apresentadas por Swedenborg (1688-1772) ou por Baudelaire ${ }^{3}$ (18211867). A ciência das correspondências propõe pontes espirituais entre as coisas: os objetos, a natureza e as pessoas. Ela é responsável por projetar uma noção de alteridade, possibilitando a duplicação reflexiva sem suprimir as diferenças entre a natureza dos corpos e o artifício dos objetos.

Uma regra comum é que nada pode existir nem subsistir depois de si, mas que toda coisa existe e subsiste depois de uma outra, quer dizer, por uma outra, e que nada pode ser contido dentro de uma forma depois de uma outra, quer dizer, por uma outra, como vemos depois de todas e cada uma das coisas da natureza. (SWEDENBORG, 1985, p.45-6)

Como explica Paz (2013), o avesso de todo desenho é o perpétuo cindir-se de si mesmo a fim de elucidar que cada coisa é metáfora de uma outra. Revela-se uma poética da analogia que não redime as diferenças, mas as insere num jogo infinito de correspondências. Tais correspondências nutriram não somente a poesia moderna, mas a experiência crítica na modernidade, experiência ligada às artes, à música, ao design, à arquitetura e à moda. A sinestesia proposta pelo tratado das correspondências tinha por objetivo alinhar a técnica à experiência do espírito, orientação que alicerça os fundamentos de criação para a vanguarda do início do Século XX. Surge daí a ciência de investigação para a composição de medida dos objetos em uma dimensão técnica e poética, como nos explica Chancerel (1998), ao abordar a problematização dos sistemas e dos fundamentos na morfologia dos objetos.

O Tratado das Correspondências, de Swedenborg, influenciou igualmente as teorias relacionadas à criação, composição, plástica e estrutura sistêmica de medidas (dos objetos, dos corpos e dos espaços) na Escola Bauhaus (ESPEJO, 1999). Os estudos fenomenológicos partiam do entendimento de uma estrutura intrínseca da consciência aberta às significações exteriores. Para Itten (1888-1967), Gropius (1883-1968), Klee (1879-1940) e Kandinsky (18661944), a ciência das correspondências representava a capacidade espiritual de abstração do pensamento lógico. Toda criação dependeria da capacidade de meditação interior que unificaria a experiência estética dos sentidos aos métodos científicos.

No âmbito da Escola Bauhaus, a prática da correspondência permitiu à teoria do design compreender as relações imagéticas como abstração das formas. O resultado extraído dessa prática conduziu às pesquisas sobre o abstracionismo, a partir do qual o signo poético adentrou o projeto, influenciando diretamente a construção conceitual dos objetos, dos espaços e das roupas de artista (nomenclatura que contemporaneamente é denominada por wearable). $\mathrm{O}$ interesse que incidia sobre a prática das correspondências estruturou as teorias acerca da obra de

\footnotetext{
${ }^{3}$ Baudelaire defendia uma teoria da imaginação como uma faculdade capaz de absorver a vida exterior por meio da contemplação. Para o poeta, a fantasia era subjetiva e não extraía das coisas a essência espiritual do ato criativo: "a imaginação é uma faculdade quase divina que percebe em primeiro lugar (...) as relações íntimas e secretas das coisas, as correspondências e as analogias”. (BAUDELAIRE apud DIDI-HUBERMAN, 2003, p.121)
} 
arte total ou do design total, englobando todas as formas de criação da arte, do design e da moda no domínio da vida.

Itten (1888-1967) se interessou pelo estudo das roupas a partir do encontro com teorias decadentistas que unificavam a criação estética às tecnologias do si. Ele estruturou não somente o atelier de tecido na Bauhaus como também iniciou as pesquisas sobre wearable. Seguindo algumas regras dos princípios do tratado das correspondências, Itten desenvolveu pesquisas sobre as formas da geometria e os elementos conceituais da forma. Ele concebeu uma teoria sobre a racionalidade moderna das formas do vestuário, propondo uma identificação do movimento dos corpos com os objetos. A observação dos fenômenos fundamentava o que ele denominava por "objetos do pensamento".

Essa teoria propunha igualmente para o design uma operação de esquematização tendo em vista a medida das diferenças associativas entre os objetos e os corpos. A prática das correspondências nada mais seria que um processo de identificação meditativa dos objetos dentro de um campo dialético no qual o pensamento crítico aproxima-se da experiência dos sentidos (aesthesis). Surgiria, dessa teoria, a construção de um método para exploração de formas abstratas que unificaria a relação entre o corpo e os objetos. Nas pesquisas realizadas pelos ateliês da Escola Bauhaus, tornou-se evidente que as roupas de artistas desconstruíam a relação pragmática entre a forma e a função. O que compreendemos atualmente como relação entre forma e função para o entendimento da prática de projeto em design estava, de fato, vinculado às teorias de espiritualização do artifício.

De acordo com Mahn (1997), a relação entre a pesquisa esotérica e a criação em design influenciou grande parte dos artistas no início do Século XX porque colocou em questão a ruptura com o dimorfismo do gênero no vestuário e a aparência burguesa normativa. A criação do costume denominado como Bauhaustracht (traje Bauhaus) é um exemplo da pesquisa de correspondência entre as cores, os sons e os movimentos dos corpos. Esse traje foi adotado pela comunidade da Bauhaus como um signo de pertencimento ao estilo de vida idealizado pela escola. O modelo era fabricado por apenas dois retângulos de cor vermelha integrando-se a recortes verticais em tons cinza.

A ideia foi incorporada às experimentações de Moholy-Nagy ao tentar corresponder as roupas ao mobiliário, à arquitetura e às imagens fotográficas. Ele comprou um uniforme de pescador para apresentar o possível diálogo entre os objetos e, a partir disso, propôs uma analogia desse uniforme às formas geométricas. A pedagogia da prática das correspondências, na Bauhaus-Dessau, também colocou em questão a ideia do Ready-Made pelo sentido da apropriação. Esse processo era desenvolvido como uma maneira de pensar a mudança de postura cultural diante das trocas simbólicas efetuadas nos usos de determinados objetos e dos vestuários. A tensão dos valores relacionados ao uso e à função provocou um deslocamento no que estava em jogo na criação do design. Por meio da prática de correspondências, refletia-se sobre a pluralidade de ações relacionadas à semântica construída pelas novas possibilidades de uso e transformações plásticas. 


\section{Existência dos corpos e dos objetos: poiesis, plástica e linguagem.}

Para Beyaert-Geslin (2011), o que estaria em jogo seria uma semiótica das práticas graças à qual os critérios de uso são descontextualizados. Dentro de um sentido epistemológico, tais correspondências contribuíram para novas inscrições dos objetos no cotidiano, transformando a sua interface com os corpos. A prática das correspondências restituiu novas estratégias para a criação e para a utilização dos objetos. Os modos de criação, de fabricação e de uso criaram ficções na estrutura social de maneira a provocar a emergência de novos contextos nas formas de vida. Em tom crítico, Griaule (1975), no texto La Poterie, afirma que algumas pesquisas arqueológicas se detêm sobre a estética dos objetos, mas não a relacionam com a posição dos corpos que utilizam os utensílios. Griaule acredita que cada artefato produzido testemunha um valor de uso, comunicando as correspondências efetuadas entre os objetos e os corpos. Os objetos têm uma vida existencial singular que orientam novos modos de vida.

Do ponto de vista de Chancerel (1998), a forma de uso dos objetos dá visibilidade à dimensão técnica da medida dos corpos. Por esse motivo, quando as correspondências no design criam analogias entre diferentes objetos, inicia-se uma construção simbólica diferenciada, introduzindo uma relação específica entre a experiência das coisas e suas práticas sociais. Para Bourdieu (2015), a alteração do processo perceptivo dos objetos no cotidiano seria determinante na demarcação da fronteira entre o design e a arte. As experiências estéticas relacionadas à forma - e não à função - seriam fundamentais na definição das etapas que distinguem esses campos. Ao citar o exemplo da carta de Panofsky (1892-1968), Bourdieu detecta certas etapas na distinção entre o utilitarismo dos objetos e a experiência estética: a carta seria inicialmente um instrumento de comunicação; na medida em que a escritura exige a adoção da caligrafia, ela adentra no território da experiência estética; caso o conteúdo expresse uma linguagem refinada, alterando a estrutura narrativa, sua linguagem se transforma em expressão poética. Como podemos ver, há, para Bourdieu, um jogo de intenções entre o autor da carta, a carta enquanto objeto e o seu leitor como um receptor.

Tanto a criação quanto a apreciação dos objetos articulam correspondências mutáveis em seu sentido. Dessa maneira, qualquer coisa inserida em nosso cotidiano pode ensejar uma experiência estética, obedecendo a uma intenção contemplativa. Essa troca simbólica é responsável por deslocar os objetos do design do campo meramente funcional para a apreciação poética. Segundo Beyaert-Geslin (2011), a intertextualidade da interface-sujeito ou da interfaceobjeto alicerça a construção conceitual de novos signos. Essa experiência dos corpos e dos objetos é a base para a elaboração de outras narrativas e novas significações plásticas, fator determinante para gerar estratégias de percepção que transformam a semiótica dos objetos.

A experiência de interação dos corpos com os objetos mobiliza diferentes construções conceituais. A reflexão sobre as analogias semânticas e visuais da prática de correspondências conduz tanto ao desvio das formas dos objetos quanto aos gestos dos corpos. O designer e o 
usuário iniciam um diálogo como uma ação de pós-produção, provocando o uso inabitual dos objetos ao permitir a elaboração de novos comportamentos perante eles. Segundo Quinz (2014), trata-se de uma experiência crítica que mobiliza o sentido interdisciplinar e transdisciplinar no design, tal como a ideia da constelação de práticas poéticas que efetuam redes de sentidos complexos e conflituosos. A correspondência das práticas ocasiona a troca entre campos, aproximando o design da filosofia, da moda e da arte. Essa estratégia é entendida como uma ação que (re)semantiza tanto a significação dos objetos quanto dos corpos, provocando uma experiência tátil a partir do choque de tensões visuais.

Nesse contexto, o objeto "estranho" se define como um objeto "pós-otimizado", que inverte as estratégias e os valores do design de interação emergente. Oposto a esse tipo de design, que tende a otimizar o uso dos objetos técnicos e a padronizá-los, o design crítico explora a disfunção a fim de produzir comportamentos desviantes com mais alto potencial estético: em lugar de ser transparente como uma interface, o objeto crítico é opaco; em lugar de ser eficaz, simples e confortável para o uso (e logo tranquilizador), ele é complexo, enigmático, ele desorienta, por vezes, repele. (QUINZ, 2014, p.39)

Para além de artefatos utilitários, os objetos se transformam em signos, índices ou alegorias. Eles são estranhos - materializam-se de forma autônoma e encarnam valores singulares, sendo compreendidos por Baudrillard (1968) como objetos para-funcionais. Dito em outras palavras, como criações que incluem em seu aspecto utilitário uma dimensão poética. O design cria uma ficção dos modos de existência desses objetos porque interfere nas ações cotidianas, produzindo uma transformação no uso e na função dos objetos. A imaginação do usuário no cotidiano trabalha potencialmente a fabulação dos objetos, (re)semantizando-os na realidade. Nesse sentido, podemos dizer que há uma produção conceitual que desconstrói a função primeira e primária dos objetos, contribuindo para a construção narrativa de outros sentidos utilitários que (re)contextualizam os usos nas práticas cotidianas.

\section{Cadeiras Vestíveis: a intração como poética do uso para o corpobjeto}

Os objetos, bem como as correspondências e interações ontológicas entre humanos e coisas, modificam nosso estar no mundo. O corpo enquanto aparato psicobiológico e o indivíduo em sua complexidade antropomórfica estão envolvidos na relação com os objetos, vivenciando uma experiência de transformação mútua. Nossa reflexão se orienta pelo conceito de intração, elaborado por Barad (2007). Trata-se de uma ideia filosófica que designa a capacidade do designer de propor uma forma de emergir do mundo para vivenciar a "dissolução do eu" (FLUSSER, 2007, p. 209). Dito em outras palavras, seria uma possibilidade de continuidade do corpo do sujeito com o objeto. Pretendemos apresentar a intração como uma metamorfose do corpo em objeto e dos corpos dos objetos. A fim de esclarecer essa ideia, criamos o neologismo pela contração semântica: corpobjeto. O termo pode sugerir os projetos em design, arte e moda que concebem o "elo inseparável entre observador e a coisa observada." (MORIN, 2015 p.12). De acordo com Barad, não se trata de duas entidades anteriores à experiência. Isso significa que 
corpo e objeto se constituirão mutuamente a partir desse encontro e essa instância de constituição é sempre relacional:

A unidade epistemológica primária não são objetos independentes com limites e propriedades inerentes, mas fenômenos. Na minha elaboração do realismo agencial, os fenômenos não marcam apenas a inseparabilidade epistemológica de "observador" e "observado"; ao contrário, os fenômenos são a inseparabilidade ontológica de "componentes" agencialmente intra-ativos. Ou seja, os fenômenos são relações ontologicamente primitivas - relações sem relatos pré-existentes. A noção de intração (em contraste com a "interação" usual, que pressupõe a existência anterior de entidades / relatos independentes) representa uma profunda mudança conceitual. (BARAD, 2007, p.333)

Podemos tomar como exemplo de intração a relação corpo-cadeira. Pettena elaborou por meio das Cadeiras Vestíveis as questões acima descritas ${ }^{4}$. O criador afirma sobre as peças que "usar é puramente comunicativo, como na performance Cadeiras Vestíveis - Wearable Chairs" (PETTENA, 2014, p. 74). Comparar o ato de utilizar um objeto, ou de vesti-lo, com uma performance vai em concordância aos argumentos que aqui construímos. A intração nos permite compreender a busca de uma vivência do objeto como ato de transformação do estar no mundo a partir do corpo e de suas relações com os objetos. Constatamos uma possibilidade de poiésis no uso, proposta pelo Design Radical. A poiésis, termo grego para o ato criativo, o ato de fazer, de trazer algo para a realidade, conduz à possibilidade de uso do objeto como ato performativo. $\mathrm{O}$ vestir poderia ser em si mesmo um ato criador e poético, como veremos na proposição a seguir, sobre a qual Brayer relata:

Por um dia, um grupo de pessoas, em uma fila indiana, se tornou auto-suficiente: eles criaram objetos desarticulados sem forma ou significado, imbuindo-lhes de algo. Cada um carregava uma cadeira nas costas, como a própria sombra. A coisa toda foi narrada, a fim de preservar sua memória, para aqueles que não estavam presentes naquele dia (...) As cadeiras foram apenas os meios apropriados para uma possível integração; desconectadas, se não usadas, elas sinalizam a necessidade da presença de um corpo para que tenham significado. Então, a partir do comportamento veio a instrumentalização da jornada para regiões desconhecidas, que por sua vez se tornaram acessíveis. (BRAYER, 2003, p.139)

Podemos ver que, ao refletir sobre a imagem e sobre a expressão de que cada um carregava a cadeira nas costas como a própria sombra, encontra-se realizada a incorporação denominada: corpobjeto. Não há mais duas categorias distintas. Como a fita de Moebius, nessa imagem não há mais um dentro e um fora, a sombra não é uma parte externa ou acoplada ao corpo, mas sim uma parte indissociável, uma incorporação. Averiguamos, a partir dos projetos, a capacidade do objeto de permitir ao corpo (re)semantizar o estar no mundo, provocando modificações nas

\footnotetext{
${ }^{4} \mathrm{O}$ projeto proposto pelo designer Pettena exemplifica algumas das ideias propostas pelos grupos relacionados ao Design Radical, movimento que buscava em suas investigações, como a própria etimologia da palavra radical aponta, teorizar uma estratégia que repensasse o papel dos atores dentro do sistema do design a partir da reflexão dos fundamentos do design, ou seja, a partir de suas raízes. Além disso, o Design Radical buscou também repensar o papel do design dentro do sistema capitalista, ou seja, as implicações dos objetos na sociedade de consumo em massa. O movimento visava, dessa forma, não apenas romper com os movimentos antecessores, mas refletir a respeito das origens e da essência do design (MOMA, 1972, pp. 255- 402).
} 
relações construídas e, aqui exemplificadas, pelo processo de intração descrito por Barad (2007).
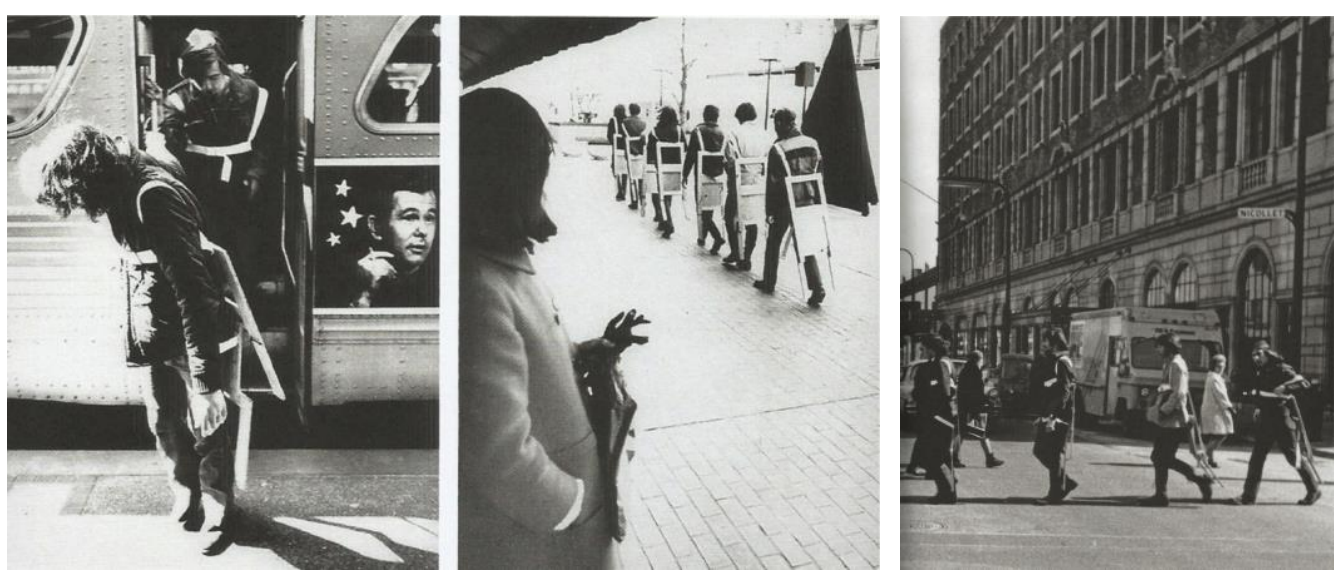

Figura 1: Gianni Pettena, Vestirsi di sedie (Cadeiras vestíveis), 1971, Performance, Minneapolis, 1971; 152x40x5 cm Fonte: DIDERO, 2017, p. 186.

A performance, realizada por dez estudantes de Pettena na Faculdade de Arte e Design de Minneapolis, apresentava os usuários portando as cadeiras nas costas como wearables. Os estudantes se deslocavam em fila, por cerca de duas horas a pé ou utilizando o transporte público, parando em trechos do caminho e, finalmente, retornando à faculdade. Em seguida, as cadeiras foram expostas com relatos e fotografias da performance, de forma a preservar a memória da ação, dialogando intimamente com os procedimentos artísticos de curadoria e expografia.
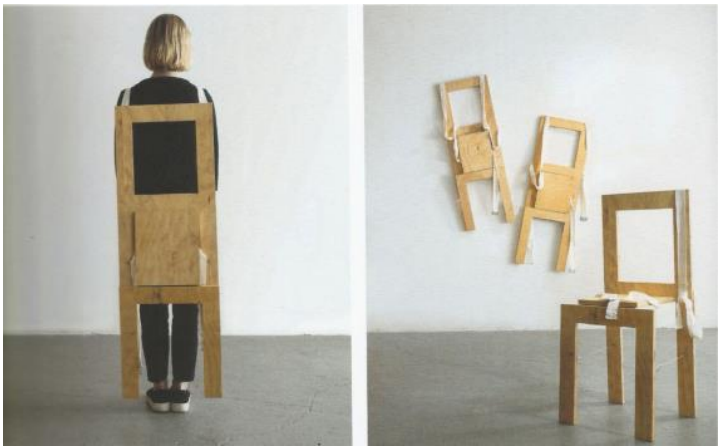

Figura 2: Gianni Pettena, Vestirsi di sedie (Cadeiras vestíveis), 1971, Performance, Minneapolis, 1971; 152x40x5 cm Fonte: DIDERO, 2017, p. 186.

Segundo os relatos, quando penduradas nos corpos e quando não estavam em uso como assentos, as cadeiras se apresentavam como tábuas bidimensionais, o que evidenciava a necessidade do corpo para que tivessem seu significado explicitado. Elas necessitavam da relação com o corpo para se tornarem cadeiras. Simultaneamente, ao portar este wearable os 
estudantes exploravam novas formas de vivenciar os espaços, o transporte público e o ambiente urbano. As cadeiras vestíveis sugerem uma interconexão entre a pausa e a mobilidade do corpo, permitindo o diálogo do corpo assentado em seu processo de contemplação com o corpo em movimento, constituindo uma possibilidade de representar a relação de intração do corpobjeto a partir da poética do uso acima descrita.

A intermitência entre ambas, a cadeira e a roupa, é potencialmente simbólica porque unifica a individualização do corpo pelo estilo advindo da moda, doando a cada sujeito na massa citadina a possibilidade de inteirar-se com o ambiente urbano de forma singularizada pelo gesto do seu próprio corpo. O trabalho aproxima-se da arte ao explicitar a estetização dos corpos nas paisagens humanas que compõem os cenários urbanos. Nesta performance, foi o corpo que ativou e deu sentido ao objeto: a cadeira enunciava significados quando transportada; caso contrário, ficava desarticulada.

\section{Considerações Finais}

Apresentamos ao longo do artigo como a prática das correspondências no design o aproxima de outras áreas, como a moda e a arte. Nossa intenção foi expor um arcabouço teórico e conceitual sobre as diferentes leituras que inscrevem a relação entre os corpos e os objetos dentro de estudos referentes à sua dimensão sociocultural, plástica e comunicacional. A correspondência das práticas advindas da moda e da arte encontram no design a possibilidade de experimentação dos novos estatutos de projeto na criação de objetos. Trata-se de objetos críticos e estéticos porque ampliam a ideia do utilitarismo no cotidiano, e apontam para a inserção de características bizarras ou estranhas como um elemento poético plástico. As linguagens do wearable propõem analogias que possibilitam aos objetos de design voltarem-se tanto para as práticas do cotidiano quanto às contemplações da experiência estética ligadas à arte.

O estudo dividiu-se em três etapas, nas quais observamos como a prática da correspondência introduz um aspecto reflexivo tanto para o criador quanto para o usuário das peças. Cria-se um modo de função ficcional a partir do qual o design propicia um jogo interativo que alinha à realidade da experiência relacional os corpos e os objetos, transformando mutuamente a cadeira em roupa e as roupas em corpobjetos moventes. A perspectiva experimental engendrada pelos projetos amplia o campo de pesquisa do design, colocando-o em contato a filosofia, a moda, a poesia e a arte. A ideia foi colocar em questão o sentido de correspondência como uma possibilidade de apresentar a alteridade entre os campos, de modo a potencializar as reflexões sobre o conceito dos objetos e sobre as práticas socioculturais ativadas pela transformação comportamental dos corpos. A prática das correspondências é um recurso pouco utilizado. No entanto, ela introduz no design o sentido do duplo como a face insólita do estranho e do bizarro na pluralidade da qual o mundo se constitui. 


\section{Referências}

BARAD, Karen. Meeting the universe halfway: Quantum Physics and the Entanglement of Matter and Meaning. London: Duke University Press, 2007.

BAUDELAIRE, Charles. Salon de 1859. Oeuvres Complètes. Paris: Robert Lafont, 2011, p.750-52.

BAUDRILLARD, Jean. Le Système des Objets. Paris: Gallimard, 1968.

BEYAERT-GESLIN, Anne. Les Chaises. Prélude à une Sémiotique du Design. In: BEYAERT-GESLIN, Anne. Semiotique du Design. Paris: Puff, 2011, pp.177-206.

BOURDIEU, Pierre. A Economia das Trocas Simbólicas. São Paulo: Perspectiva, 2015. BRAYER, Marie-Ange. Gianni Pettena. Milão: Silvana Editoriale, 2003.

CHANCEREL, Jean-Louis. Théorie de la Mesure et Objets. In: Espace géographique, tome 17, n³, 1988. Qualité de la vie, "bienêtre", indicateurs sociaux et disparités territoriales. pp. 218-231.

DAUTREY, Jehanne. QUINZ, Emanuele. Strange Design: Du design des objets au design des comportements. Paris: It: éditions, 2014.

DIDERO, Maria Cristina. Super Design: Italian Radical Design 1965-75. New York: Company and The Monacelli Press, 2017.

DIDI-HUBERMAN, Georges. L'Immanence Esthétique. Alea. V5, Jan/Jun 2003, p.118147.

ESPEJO, Arturo. Les Sens Caché du Rationalisme Moderne. In: Política Hermetica, $\mathrm{N}^{\circ} 12$, Paris: Sobornne, 1998, pp. 101-132.

FLUSSER, Vilém. O mundo codificado. São Paulo: Cosac Naify, 2007.

GRIAULE, Marcel. La Poterie. In: GRIAULE, Marcel. Dieu D’Eau. Paris: Arthème Fayard, 1975, pp. 100-102.

HEIDEGGER, Martin. O que é uma Coisa. Lisboa: Edições 70, 1992.

HUYSMANS, J.-K. Às Avessas. São Paulo: Cia das Letras, 1989.

MAHN, Gabriela. Autour de Sophie Taeuber et Johannes Itten. In: EUROPE (19101939) QUAND L’ART HABILLAIT LE VÊTEMENT. Paris: Paris Musées, 1997, pp.114123.

MOMA, Catálogo. The new domestic landscapes. New York, 1972.

MORIN, Edgar. Introdução ao pensamento complexo. Porto Alegre: Sulina, 2015.

PANOFSKY, Erwin. Estudos em Iconologia. Lisboa: Estampa, 1995. 
PAZ, Octavio. Os Filhos de Barro. São Paulo: Cosac Naif, 2013.

SWEDENBORG, Emmanuel. Traité des représentations et des Correspondances. Paris: la Différence, 1985.

STEYERL, Hito. The Language of Things. European Institute for Progressive Cultural

Policies (eipcpp), Viena, Jun. 2006. In: PIMASP 2016-17. PROGRAMA INDEPENDENTE DO MUSEU DE ARTE DE SÃO PAULO. São Paulo: PIMASP, 2017, p.8.

\section{Sobre as autoras}

Adriana Dornas Bacharel em Desenho Industrial, Mestre e Doutora em Design/UEMG. É pesquisadora e curadora de design contemporâneo no MUC - Museu da Cadeira Brasileira, onde pesquisa sobre design-arte e design autoral, permeando a arte, a moda, a arquitetura e o design.

Angelica Oliveira Adverse é Bacharel em Desenho, Doutora e Mestre em Artes Visuais (EBA/UFMG). Residente pós-doutoral no Programa de Pós-Graduação em História/UFMG. É Professora Adjunta da Escola de Belas Artes / UFMG e do Programa de Pós-Graduação em Artes / UEMG. Pesquisa no campo da Filosofia da Arte, Estética, História da Arte e História da Moda, desenvolvendo estudos sobre Wearable a partir de relações entre a arte, a moda, o design e a arquitetura.

Maira Gouveia é Bacharel em Design de Moda (EBA/UFMG), mestranda e pesquisadora do Programa de Pós-graduação em Design na Universidade do Estado de Minas Gerais. Atuou como docente na ARCH Academy of Design em Jaipur, Índia. Estuda as relações entre corpo e objeto nas intersecções entre arte e design. 